\title{
Toward a Biopsychosocial Ecology of the Human Microbiome, Brain-Gut Axis, and Health
}

Karl J. Maier, Ph.D.

Salisbury University

Department of Psychology

Mustafa al'Absi, Ph.D.

University of Minnesota Medical School

Department of Family Medicine and Community Health

Department of Biobehavioral Health and Population Sciences

\section{Corresponding Author:}

Karl J. Maier, Ph.D.

Department of Psychology

305 Holloway Hall

Salisbury University

1101 Camden Avenue

Salisbury, MD 21801

410-543-6374 (office)

$410-548-2056($ fax $)$

kjmaier@salisbury.edu

Conflicts of Interest and Source of Funding: None 


\section{Abstract}

OBJECTIVE: Rapidly expanding insights to the human microbiome and health suggest that Western medicine is poised for significant evolution, or perhaps revolution - this while the field continues on a trajectory from reductionism to a biopsychosocial (BPS) paradigm recognizing biological, psychological, and social influences on health. The apparent sensitivity of the microbiota to perturbations across BPS domains suggests that a broad and inclusive framework is needed to develop applicable knowledge in this area. We outline an ecological framework of the human microbiome by extending the BPS concept to better incorporate environmental and human factors as members of a global, dynamic set of systems that interact over time.

METHODS: We conducted a selective literature review across disciplines to integrate microbiome research into a BPS framework.

RESULTS: The microbiome can be understood in terms of ecological systems encompassing BPS domains at four levels: (1) immediate (molecular, genetic, and neural processes); (2) proximal (physiology, emotion, social integration); (3) intermediate (built environments, behaviors, societal practices); and (4) distal (physical environments, attitudes, and broad cultural, economic, and political factors). The microbiota and host are thus understood in terms of their immediate interactions and the more distal physical and social arenas where they exist.

CONCLUSIONS: A BPS ecological paradigm encourages replicable, generalizable, inter/transdisciplinary research and practices that take into account the vast influences on the human microbiome that may otherwise be overlooked or understood out of context. It also underscores the importance of sustainable bio-environmental, psychological, and social systems that broadly support microbial, neural, and general health.

Keywords: microbiome; microbiota; brain-gut axis; biopsychosocial; ecology; environment; antibiotic resistance BPS $=$ Biopsychosocial 
"Nowhere can one see more clearly illustrated what may be called the sensibility of such an organic complex, expressed by the fact that whatever affects any species belonging to it, must have its influence of some sort upon the whole assemblage. He will thus be made to see the impossibility of studying completely any form out of relation to the other forms; the necessity for taking a comprehensive survey of the whole as a condition to a satisfactory understanding of any part." (Stephen A. Forbes (1887) (1).

\section{Introduction}

Four decades ago, George Engel's provocative treatise on a new biopsychosocial (BPS) model (2) initiated the contemporary evolution in Western medicine from a largely reductionist biomedical paradigm toward wide acceptance of biological, psychological, and social influences on health, as reflected in the growing emphasis on behavioral and social sciences in the Medical College Admission Test, and the training of physicians more generally $(3,4)$. Now, rapidly expanding research on the human microbiome (the genome of all microorganisms living in and on us) and the microbiota (the collection of the microorganisms themselves) (5) with their wideranging health implications could suggest that medicine is undergoing yet another significant evolution, or perhaps even revolution (6). At the core of this emerging literature has been a proliferation of knowledge gained from animal and human studies examining the microbiota of the brain-gut axis in particular for its richness and apparent role in mental and physical processes related to healthy functioning and disease (7).

As with the historic origins of the biomedical model, this emerging trend is again largely focused on the microbial world, though now understood as exceedingly more vast and complex. The biomedical focus on pathogens and cellular pathologies in general has made, and will continue to make, immeasurable contributions in identifying focal points of intervention for 
many diseases. But with this progress comes the realization of limits to abstracting health and disease from the broader context of the whole person and their inhabited world. Likewise, we have recently gained much insight from studies attempting to isolate the role of particular taxa (organism types) within the gut. Continuation of this basic work is essential. However, there is growing appreciation that this approach is limited, and that an ecological paradigm is needed to better understand the nexus of human-microbiome health and its context (8-13).

A decade ago, leading microbiologists advocated that, "It is time to breach the institutionalized dichotomy between environmental science and biomedical research, and to study ourselves as an integral and dependent part of our microbe-dominated world." They imagined epidemiologists of the future "describing how changes in kilometre-scale macroecosystems affect micrometer-scale microbial ecosystems associated with populations of meterscale human beings, on time scales of an infection, a human lifespan, or the rise and fall of a society" (14).

As basic and applied research develops on the microbiome and the brain-gut-microbial axis, the functional integration of this work in medicine will be achieved best through research that is conceived from a broad, comprehensive framework that considers the evolutionary significance of our broadest environments to the neuroscience of mind-body substrates. An ecological framework, extending the widely accepted BPS model (2), was developed and presented by one of the authors of this article (K.M.) at the American Psychosomatic Society American Gastroenterological Association Symposium, Brain-Gut Interactions and the Intestinal Microenvironment held in New York, NY, USA in October, 2015 (15). Here we 
outline this concept to guide future investigations of the human microbiome, brain-gut interactions, and health. Centering on the gut microbiome, we integrate concepts and empirical findings across multiple scales within a unifying ecological paradigm that spans disciplines as wide-ranging as psychology and environmental microbiology.

\section{Biopsychosocial Ecology}

Ecological systems are typically characterized by various levels of interrelated processes, and may be understood as complex adaptive systems (16). Applied to the broader biosphere, complex adaptive systems can account for regularity and patterns observed at higher levels of scale (e.g., climate) that emerge from dynamic, nonlinear processes at lower physical or organismic levels (17); the biosphere evolves according to the dynamics of its component complex adaptive systems and ecosystems, ultimately feeding back to underlying, individuallevel dynamics (17). Likewise, emergent properties of microbes such as particular host responses or metabolic processes (18) reach across temporal and spatial scales, but they are most immediately the result of interactions among underlying organisms and their environment (18, 19), and reflect the highly communal nature of microbes (20). General models for emergent properties of ecological systems exist (19) and technology to study these systems is ever improving $(18,21)$. With the human microbiome, these approaches can examine the complex nonlinear dynamics of the microbiota over time and spatial scales (22), and help us begin to appreciate the more complete ecology of the microbiome within the host (23) and the broader context of the natural environment $(5,9,13,14)$.

Ecological models of health behavior (24-26), chronic pain (27), and human development (28) have advanced our understanding of the complex determinants of human health across various levels of influence. And, initiatives exist that seek a unified understanding of human, 
animal, and environmental health (e.g., "One Health," "ecohealth," and "conservation medicine") $(29,30)$. However, ecological models with range enough to capture the myriad influences on and from the human microbiome have not been clearly articulated in a single, integrative framework.

The proposed model (Figure 1) suggests that health of the gut microbiota, neural systems, and their synergies depends on the host's immediate microbial ecology and the physiological and psychosocial systems proximal to that ecology. These systems are in turn influenced by the natural and built physical environments and psychosocial systems at broader scales in which vast constellations of microbial ecologies and humans participate. Whereas BPS systems have historically been considered along traditional biological, psychological, and social boundaries, an ecological framework explicitly considers environmental and human factors as members of a dynamic global system that is determined and fluid across multiple levels, within and between biological, psychological, and social domains over time.

\section{Domains of Scale}

Here we survey the most recent findings on the microbiome and frame them within BPS domains and levels of scale as implied by the literature. As ecological boundaries are inherently permeable, our designations of domain and scale were selected for heuristic value and should be interpreted loosely. Accordingly, Figure 1 is intended to convey the context of the microbiome as expansive and fluid. In covering multiple bodies of literature, we encourage readers to consider the many possibilities for developing interdisciplinary research initiatives reflecting this ecological concept. 


\section{Immediate/Micro Systems}

The human gut microbiota, and microbiome more broadly, are increasingly appreciated as ecological systems representing the dynamic interplay of human factors (e.g., genetics and immune system) and microorganisms $(8,9)$ that we consider as the immediate level of analysis. The intestinal tract houses a tremendously diverse community of primarily bacterial organisms, far outnumbering cells of the human body, and representing a microbiome 150 times larger than the human genome (31). The dynamic interplay among these organisms - and between them and the immediate physiology of the enteric nervous system - is significant. Indeed, there is growing consideration of dysbiosis (imbalance/disruption) of the microbiota and critical host-microbiota interactions in disease, rather than the simple presence or absence of specific taxa $(8-11,32)$.

Host genes may interact with other factors to influence composition of the gut microbiome $(33,34)$, and in turn, microbes may exert epigenetic effects (35) and shape their immediate environments in profound ways by producing biofilms and metabolites (36). Such behaviors/traits may occur for reasons that are evolutionarily significant or not to the "niche construction" of the microbe's environment, and that have a range of "social" implications for the microbe itself and other organisms that may be beneficial or detrimental across time and locations within the host (36). This can affect the survival and function of microbes, pathogens, and host systems through immune and other mechanisms related to microbial community structure and function $(36,37)$. For example, novel interactions within and between bacterial and fungal species and their resulting biofilms have recently been identified and related to the inflammatory processes of Crohn's disease (32). 
The complexity of these host-microbe interactions and their consequences are profound, affecting resistance to pathogens (9) and relating to perhaps most or all biological health processes from early development to old age (6). So interconnected are these processes and systems that the microbiome has been considered an organ (38) or - when understood as a composite of the microbiome, human genome, and metabolic processes - a "human supraorganism" (5). This fundamental integration of human and microbial processes arguably reflects how the microbial world has coevolved with and shaped the human immune system (39) as it has the broader physical environment (40) and life itself over billions of years (41).

\section{Proximal Systems}

Proximal to the immediate micro-level ecology, are the systems that directly affec atnd are affected by these integrated human-microbial processes. Decades of research on the brain-gut axis has elucidated bidirectional relations between the central nervous system and the digestive system, with implications for cognitive and emotional states, functional and inflammatory gastrointestinal disorders, obesity, and even anorexia (42). In this context, the gut microbiota may be integral to fundamental processes including brain development and function $(41,43)$, and may play a significant role in metabolic processes (44), obesity (45), and eating-related behavioral propensities in animals and humans (46-48).

The microbiota also appears to play a role in the development and regulation of the immune system relevant to inflammation, auto-immune diseases, and neurological conditions $(39,49,50)$. Research is also relating diseases of mucosal inflammation of the gut and the lungs, suggesting a common lung-gut axis whereby common clinical targets may be identified within the gut microbiota for seemingly distinct inflammatory conditions such as irritable bowel disease and asthma (51). Other systems are also are ripe for investigation such as a role of the gut microbiota in cardiovascular function and health (52), particularly given the role of the vagus nerve in both brain-gut communication and cardiac regulation. 
These physiological systems are integrally related to other proximal systems in the psychological (e.g., emotion) and social (e.g., interpersonal interactions and networks) domains. Together, these systems provide context for understanding the interrelations of stress, the microbiota, and the brain-gut axis. In this regard, the gut microbiota may be both affected by stress and emotion, and play a critical role in emotional experience, early formation of physiological stress responses, and a range of stress-related pathologies, including visceral pain conditions $(53,54)$. Stress-related neuroendocrine and behavioral responses may affect the gut microbiota through effects on gastrointestinal function, metabolism, and immunomodulation. Dysbiosis of the microbiota may in turn affect these same processes (55). Stress might also affect neurodevelopment through the microbiota's direct impact on immune and inflammatory processes, and through neuroendocrine-mediated inflammation (55).

There is also evidence from animal models that composition of the gut microbiota can be manipulated to both initiate and reverse a range of behavioral states associated with anxiety, depression, and sociability (56). In part, this could be due to metabolites of microbes which include neuroactive compounds such as gamma-aminobutyric acid (41, 57). Metabolites also may have epigenetic effects (35) that could have far reaching implications for psychosocial functioning and the neurodevelopmental sequela of early life stress (55). However, translation from animal models to humans needs clarification with regard to neurobiological pathways and operationalization of emotion $(56,58)$.

In humans, a pilot study on temperament of Korean adults found an enterotype dominated by Bacteroidaceae to be associated with greater novelty seeking and reward dependence than an enterotype dominated by Prevotellaceae (59). For emotion, pre-clinical data and limited findings with humans support the exploration of psychobiotics (psychoactive probiotics) that could have targeted cognitive and emotional effects $(41,57)$. However, the potential for psychiatric interventions is currently unclear (60). 
Proximal social factors, such as family structure, and interactions with other people and animals, may also influence the composition of our microbiome $(39,61)$. In humans, recent findings indicate that spore-forming bacteria of the gut comprise a substantial proportion of the intestinal microbiota and evidence a high rate of turnover, suggesting that spores are an important mechanism by which colonization between humans may occur over time and distance (62). In rhesus monkeys, greater similarity of gut microbial community structure has been observed within prescribed social groups compared to between groups (63). Some have suggested that social bonds and relationships among primates have evolutionary significance for survival through the associated sharing of microbial communities (64). Conversely, social disruption and other forms of stress in animals may affect composition of the gut microbiota and, accordingly, immune function $(50,65)$. Finally, animal models of autistic spectrum disorders suggest that behaviors associated with sociability may be affected by health of the gut microbiota and its immediate host environment $(56,66)$.

\section{Intermediate Systems}

A range of factors may be considered at the intermediate scale of analysis that operate between the proximal-level systems just described and the most distal. For the human microbiome, considerable variability in apparently normal profiles of the gut microbiota can be observed by geographic region (67). Variation in exposure across different inhabited physical environments of the host may be one of many determinants of the so called "variable microbiome," referring to the set of microbe genes found in some but not all humans (versus a core microbiome common to most all humans) (5). Diversity is inherent to the microbial world, with microbes evolving ("vertically") within genetically related phyla. Horizontal gene transfer also takes place between less related organisms, initiated by environmental changes that call for 
adaptation (68). This appears to occur within the gut, and across humans, animals, and geographic space, supporting a broad ecological understanding of the human microbiome (69). Diet may be one source of gene transfer from non-human to human microbes, accounting for our evolved ability to break down a range of carbohydrates (70).

In the psychological domain, dietary behavior appears to be a key determinant of the gut microbiome, although these effects are confounded by host genetics and a range of social and geographic factors $(71,72)$. Consistent with other known health risks, diets high in fat versus plant-based, high fiber diets tend to be differentially associated with the composition and function of the gut microbiota as well as obesity and inflammatory markers $(71,73)$. In one study, high protein consumption and intense exercise habits among professional rugby players were associated with greater diversity of the microbiota compared to non-athlete controls (74). Although the independent effects of diet and activity on diversity remain unclear, some types and intensities of physical activity may affect the gut and intestinal microbiota in ways that could affect risk for intestinal inflammatory problems (75).

Spanning many individual behaviors, psychosocial factors can have important influences on the microbiota. In particular, widespread antibiotic use and misuse is a global problem (76) that represents one of the most significant assaults on the integrity of the human microbiome (77) and broader microbial ecosystems (78). In 2010, U.S. pharmacies sold 73,620,748,816 doses of antibiotic medications (79). However, the majority of antibiotics globally are used on food animals, with conservative estimates at over 60,000 tons in 2010 alone; this amount is expected to nearly double by year 2030 due to the growth of intensified agricultural practices in developing nations (80). Although research is needed to quantify the impact on the human microbiome, one can appreciate that this scale of usage likely has significant implications for 
microbiomes of humans, animals, and the soils of our broader environment (78). Excessive and inappropriate use also accelerates the emergence of resistant bacteria (81) relevant to our built and natural living environments (78), which may influence the human microbiome and risk for infectious disease.

The increasing practice of Caesarian deliveries in many developed societies may be considered another significant intermediate-level factor contributing to altered microbiomes in those populations over recent decades (77). Whereas vaginal delivery initiates normal microbial colonization from the mother at birth, infants born surgically show a different microbial colonization that may predict a range of health risks into adulthood, including asthma and allergic diseases (82). Although these birth delivery effects on the microbiome may be somewhat modifiable (83), much is not known with regard to the extent of differences in microbial composition and how it may change or fully affect health over time. As Caesarian delivery is sometimes medically indicated and sometimes elective, intermediate-level policies and practices relating to the procedure, as well as the education and behaviors of medical providers and the public may become important psychosocial factors to study.

Compared to early establishment of the microbiota at birth, subsequent colonization appears to be increasingly determined by environmental exposure (84). Microbes in our built and natural environments may have beneficial and detrimental effects on the microbiota and health $(39,85)$. Rook and colleagues (86), highlight the general importance of early life exposure to a diversity of microbes in our natural environments for developing an individual's regulatory immune response to commonly encountered agents. An increasing proportion of the global population lives in urban settings (87) or amidst micro-level ecosystems that are impoverished due to the ubiquity of highly managed and monocultural landscapes (13). In contrast to an 
abundance of common infectious microbes, urbanized environments are notably devoid of "ancient" microbes; humans and their immune systems are thought to have evolved to tolerate a range of these so-called "old friends" through early life exposures in natural environments that support the development of immune regulation. Increased urbanization with its limited provision of these microbes is thus associated with commensurate increases in systemic inflammation and related conditions among residents (86).

Beyond these potential developmental effects, little is known about how living environments affect the human microbiome itself. In the other direction, the microbial profile of at least some interior environments may largely reflect passively accumulated remnants of the microbiome directly and indirectly transmitted from humans (88). However, these environments likely evolve over time, influenced by outdoor microbiomes and selective pressures from materials and biocides used in buildings (87). Thus, microbiomes of interior environments show commonalities, but also variation according to geographic region, occupancy, and a range of outdoor and human influences (89).

\section{Distal Systems}

The distal level of scale includes living and non-living natural environments in the biological/physical domain, and their interface with broad economic, political, and cultural phenomena in the social domain. In the psychological domain, distal factors include constructs such as individual awareness of and attitudes about natural environments and social systems. The extent of an individual's awareness of these factors determine the extent to which they are psychologically affected by these environmental and social processes, and conversely, to what extent they willfully engage in determining them. 
The World Health Organization (WHO), One Health, and other global entities have identified global ecological health, and biodiversity in particular (at all levels, including microbes) as the primary determinant of human health (78). At the most distal level, our broad physical environment is inhabited and even shaped by a vast universe of microbial life (40). Efforts to measure and catalogue this are underway (90), but the full extent of that world is not known, much less how our participation in it may affect the human microbiome. One can observe, however, that environmental degradation and changes in biodiversity seen in broader environmental ecosystems in recent decades (91) parallel rapid increases in a range of diseases associated with disrupted microbiota in developed societies over this time $(8,77,85)$. As with our built environment, mounting evidence suggests that biodiversity of the natural environment plays a significant role in the development and composition of the human microbiome and earlylife immune programing, with decreased microbial diversity likely affecting immune development and non-communicable disease risk $(13,39)$.

Globalization of social and economic activities have far reaching planetary impacts, including the integrally related problems of climate change, biodiversity loss, and environmental degradation $(92,93)$. Indeed, there is ongoing consideration of the "Anthropocene" as a geologic epoch to follow the Holocene because of these impacts (94). With diet being a major influence on the gut micro environment (71), these distal-level ecological systems affected by industrialization and globalization are of likely importance given the role of ecological health in the food supply.

In general terms, there are cultural, geographic, and economic factors that determine agricultural and dietary practices, along with individual awareness and attitudes. In turn, these factors affect the state of our physical natural environment through agricultural practices that 
affect the very structure and quality of ecosystem services available to us from that environment. More specifically, there is a clear trend globally of decreasing local/regional biodiversity and, consequently, less diversity and quality of food, as intensified agricultural practices accelerate. This has been occurring with industrialized nations for some time, but it is now rapidly increasing among indigenous populations, fueled in part by globalization, economic pressures, and the need to feed a growing global population $(78,95)$. This increasingly manifests as monocrop agriculture and imported diets of meat, fat, and high energy foods that significantly influence composition of gut flora and associated risk for non-communicable diseases (96). These dietary trends reflect the so called "diet-environment-health trilemma" for their negative health effects and collateral promotion of deforestation, and increased green-house gas emissions due to the energy inefficiency of producing these types of food (97). This contrasts with more resource-efficient locally-sourced or traditional diets that rely more on cultural knowledge and sustainable practices that generally support local biodiversity, nutritious food, and social structures. Finally, other than agriculture, the global proliferation of non-caloric artificial sweeteners as the most widely used food additive may functionally modify the gut microbiota and increase susceptibility to metabolic disease consistent with mechanisms of glucose intolerance in humans (98).

As with food, the now rapid emergence of resistant bacterial infections is partially determined by policies and practices that are influenced by distal economic and social factors (99). Addressing this problem will require innovation and societal changes given the magnitude of antibiotic use in humans and food animals. For example, demand for traditional antibiotics may be reduced through selective use and novel disease prevention efforts (81). Modifying current antibiotic use will require that we address a range of distal psychosocial factors including 
economics, awareness, education, and training that determine use (99). A range of alternatives to antibiotics also exist in various stages of development - such as vaccines, antibodies, probiotics, and immune stimulation - that may help prevent or treat infections in ways that do not encourage resistant organisms $(81,100)$. Although these options are promising, the success or failure in developing them is rooted in distal-level factors such as international cooperation, funding, and economic forces $(100,101)$.

\section{Synthesis with Contemporary Health Challenges}

The preceding literature indicates that the microbiota may play a significant role in both non-communicable and communicable disease. This is best understood in ecological terms as the microbiome interacting with various levels of biological, psychological, and social factors across time as a dynamic system. This system may best be considered as fluid and without firm boundaries. The following examples briefly illustrate how this ecological concept can inform our understanding of non-communicable and communicable disease.

One important determinant of non-communicable disease risk is socioeconomic status, with poorer health more commonly observed in lower socioeconomic strata worldwide (78). At the distal and intermediate levels, socioeconomic disparities and geographic variation in the quality of natural and built living environments may differentially affect the brain-gut-microbial axis and non-communicable disease risk through environmental (86) and behavioral exposures (e.g., pollution, smoking, etc.), as well as food type and quality $(72,78)$. At the proximal and immediate levels of analysis, low socioeconomic status individuals may be particularly vulnerable considering their associated elevations in stress (102) and the impacts of stress on the microbiota that may relate to health over time $(50,55)$. 
Socioeconomic burden is also known to affect disease through a range of proximal-level physiological processes including inflammation (103), which tend to vary across demographic groups (104). Urbanization in general is associated with impoverished microbial exposure from natural environments, which may contribute to greater prevalence of chronic inflammatory conditions among city dwellers $(13,39)$. But risk of inflammatory disease is pronounced among urban residents living in poverty. One potential explanation is that greater inflammation associated with the stress and various insults of living in low socioeconomic status conditions is added to, or interacts with, inflammation already elevated from urbanized living (86). In addition, cognitive appraisals, emotion, racism, and education level - which may be thought of as proximal and intermediate factors - have been observed to either mediate or moderate effects of socioeconomic status on inflammatory markers, with effects evident from early life through middle adulthood (105-111). Thus, distal influences on health such as socioeconomic status may affect risk for non-communicable disease by interacting with a range of more proximal factors, the microbiota, and related physiological systems over time.

An ecological approach can illuminate the challenge of communicable disease as well. Globally, antibiotic use (79) and resistance (112) have increased dramatically in recent years. Antibiotic resistance may affect humans through multiple pathways along the food chain and through the emergence of and exposure to novel antibiotic resistant genes in the environment more generally (112). The processes of horizontal gene transfer occur in the face of environmental change, and are especially prompted by anthropogenic pollution, including antimicrobial compounds that persist in the environment. In addition, DNA molecules associated with resistance can last in isolation for considerable amounts of time (68). The globallyconnected nature of the microbiome therefore helps account for how antibiotic resistant genes 
appear to be transferred between humans and animals, and across large geographic areas, without actual infection by a resistant organism (69). Indeed, similar proportions of antibiotic resistant genes have been identified in the gut microbiota of humans across continents (113).

At the immediate/micro level, use of antimicrobial agents clearly affects the host microbiota in ways that are both known and unknown. This in turn may directly or indirectly affect proximal systems related to physiology, emotion, and perhaps, even social integration. At the intermediate level, usage behavior of antibiotics and antimicrobials occurs in the context of other intermediate sociocultural factors with broader implications. For example, sociallydetermined practices and policies allow for antibiotic-laden human and animal waste to be released into the environment through wastewater treatment and placement on fields as fertilizer. And, reclaimed water used to irrigate parkland has led to the presence of antibiotic resistant genes in those soils (114). More distal influences on antibiotic resistance include economic, cultural, and policy factors worldwide (101). For example, the proportion of antibiotic resistant genes in human fecal samples has been shown to vary according to antibiotic use policies and the duration of use by country (113). Policies that determine use of antibiotics and the development of alternative approaches that can both minimize environmental toxicity and slow the emergence of drug-resistance $(81,100)$ are therefore critical social factors that need consideration.

Resistant organisms are only part of a larger health and biodiversity crisis being realized at multiple organismic levels associated with pesticides, herbicides, and active pharmaceutical ingredients that include antimicrobial and other endocrine-disrupting compounds $(115,116)$. In addition to antibiotic resistance, loss of biodiversity may interact with multiple other factors to affect the microbiome and risk of infectious disease in general. For example, in larger species, declining diversity of wild animal hosts for vector-borne pathogens, forest fragmentation, 
changes in climate, and intensified livestock and farming practices often translate into more rapid development and transmission of infectious agents $(93,95)$. Likewise, human-induced changes in environmental landscapes and rapid changes in climate may have profound implications for the microbiomes of landscapes, aquatic ecosystems, and the global food supply (13, 93). Diversity at the micro level may be important given the role of the immediate host environment, microbial community assembly, and interactions among microbes in mediating the success or failure of pathogens and parasites $(9,117)$. Furthermore, stress has shown associations with diversity of the microbiota in mice and impacts on immune function and susceptibility to infection (65). Appreciating the interdependence of proximal host systems and biodiversity across levels of scale is therefore important if we are to better predict host outcomes and accordingly develop infectious disease prevention and control practices. This is particularly important now in the context of a changing climate where parasite and pathogen emergence and survival may be affected in unknown ways $(93,117,118)$.

\section{Implications}

Laboratory advances are continually identifying new species and their properties $(62,84$, 119), and evolutionary accounts suggest that the microbiome is not static, but constantly evolving within various time scales, determined by factors as immediate as microbial metabolites and as distal as climate. The preceding literature suggests that the principles of ecosystems in general $(17,18,120)$ are important for understanding these dynamic processes $(14,22)$. However, even in the relatively established field of ecology it is becoming clear how little is known about trends in biodiversity across most life forms when different spatial and temporal scales are considered, or the full meaning of changes at these various levels (120). For example, average constancy of species richness can hide substantial change in species type over time 
(120). Likewise, in the nascent field of human microbiome research, the level of analysis from species to strain can greatly affect conclusions regarding stability of the microbiota over time (84). Therefore, what we observe at the micro level of analysis in a particular laboratory or clinical investigation may be of limited generalizability without considering broader contextual and temporal influences on those observations (121).

Modeling the complex ecology of the gut microbiome is challenging in itself (23), so the additional consideration of a vast number of interacting broader contextual factors is a formidable task that should be considered an aspirational goal if medicine is to make durable progress in this area. A decade ago, the field of environmental microbiology was likened to the study of "a billion universes," with a need for concilient theory (i.e., unifying specialized areas of knowledge) to push beyond the largely cell-by-cell descriptive nature of work to that point (122). As the bidirectional influences between human and broader environmental and social systems become ever more clear, there is a need for collaboration and modeling approaches that embrace the inherent transdisciplinary nature of these interactions (123) in order to span the artificial divide between environmental and biomedical sciences (14). This can best be accomplished in microbiome research when investigators from diverse disciplines formulate research agendas that transcend traditional boundaries and actively harness a range of perspectives $(8,13,15,124)$.

The proposed ecological framework encourages the development of ecologically valid hypotheses for testing through consideration of a broad range of factors across levels and domains of influence that we might measure, control, or at least consider in the interpretation of empirical results. Those who study the microbial ecology of built environments are meeting a 
similar challenge by delineating a range of parameters that the literature suggests may influence their primary point of analysis, including building design, operation, and occupancy (125). Perhaps building on existing guidelines (126), a road map with an even broader view is needed to study the more complex human microbiome.

Such a comprehensive approach can help overcome present limitations in determining causation due to the largely correlational and cross-sectional research to date. For example, at the immediate/micro level, traditional statistical approaches are giving way to more complex modeling technology that can better examine and predict the interactive nature of many variables over time and scale $(22,23,127)$. In addition, some researchers advocate for using available and developing technology to examine a "multi-omics pipeline" to better reveal how microbes differentially function in varied habitats across the levels of genes, gene expression, proteins, and metabolites (21). On a larger scale, spatial environmental mapping data is one tool currently available that can examine landscape markers at various scales - including measurable characteristics of vegetation, air, and soil - that may serve as proxies for microbial exposure to examine potential links between environmental microbiota and health outcomes over time. Of particular interest here may be potential nonlinear dose-response associations between level of environmental exposure to key “old friend" organisms and health outcomes (13).

In the epidemiology literature, current and developing analytic approaches, study design considerations, and readily available statistical tools have been outlined to study the relations of intermediate and distal factors with the microbiome $(121,128)$. To address the primary challenge of large observation-to-variable ratios, "big data" and machine learning approaches that consider context in microbiome research (11), and that are used commercially for pattern recognition and prediction, such as association rule mining, may prove useful for identifying associations across 
myriad variables for further study (121). Open access data sharing and software will also be vital for progress (15). These are increasingly available $(84,127)$, and could eventually include crowdsourcing to address current limitations on sampling and geographic reach (21). Beyond obtaining big data, there have been calls for funding sources and mechanisms that are broad in scope, along with a set of common standards and a centralized data framework to merge findings from many levels of scale that are currently fragmented across investigators, funding sources, and methods $(21,121,129)$.

On the applied side, progress in developing reliable interventions and public health efforts are also challenged by the tremendous variability across individuals, age, culture, and geography that make defining "normal" gut microbiota or dysbiosis elusive (130). This variability, small sample sizes typical of intervention studies, and correlational study designs are again significant hurdles to overcome in developing clinical applications $(15,121,131)$. Yet, according to one recent review, advances can be seen in optimizing the microbe-host nexus through microbe nutrient input (e.g., diet \& prebiotics), introduction of microbes (e.g., fecal transplant \& probiotics), and eliminating problematic organisms (e.g., targeted antibiotics \& bacteriophages) (131). The next few years may hold considerable promise for innovation in treatment of Clostridium difficile infection $(131,132)$, and modulation of the developing gut microbiome of children in particular given their relatively malleable biomes (131).

But despite potential short-term benefits, we suggest that an exclusively micro-level paradigm for discovery and intervention is limited given the inherently evolving nature of the microbiome and the significant contextual influences on it. This, and the highly communal nature of microbes, lead some authors to suggest that we take an "adaptive management" clinical approach, employing an iterative process of assessment and intervention that is sensitive to 
changes in an individual's microbiome, rather than assume a static or universal healthy microbiota $(9,14)$. This is consistent with the ongoing difficulty in identifying common signatures of dysbiosis in clinical populations, such as with functional and inflammatory gastrointestinal disease (133). Rather than reductionistic, we suggest that understanding dysbiosis on a personalized level (9) underscores the importance of contextual influences and time on the microbiome and disease (11).

An ecological paradigm of the microbiota-health nexus also implies that more is at stake than individual health if we take an exclusively micro focus. This is illustrated by the tremendous success of antibiotic medications now being qualified by potentially significant negative impacts on the human microbiome, broader ecology, and subsequent health. Although the success of antibiotics has also brought us to discover the very microbial world that is under threat by them and the potential of that world to transform the way we understand and treat disease - the full irony is seen with the emergence now of a "post-antibiotic era" in which that microbial world is evolving to render current antibiotics ineffective against the very diseases that defined their success (112).

The continually evolving nature of the microbiome and the broad contextual influences outlined in this review suggest that if efforts to intervene are too myopic, at best they will be of limited use over time. However, on the path toward this, it is conceivable that an increasing number of null findings are reported (or fail to be reported given publishing bias) if studies with unmeasured or uncontrolled influences make it prohibitive to reliably discern signal from noise. Such a trend could prematurely thwart interest by researchers, funding agencies, and the public to support microbiome research. This could be a tremendous opportunity missed for advancing health. 
An exclusive focus on breakthroughs and advances at the micro level could also lure us away from better understanding and managing the environmental contextual factors that may have greater, more fundamental impacts on microbiome health than focal interventions ever could. A path toward reductionism again, albeit now more complex, could thus have an opportunity cost of failing to attend to environmental threats that are paramount. Although technological advances in the area of microbiome technology hold some promise for addressing some of these environmental challenges through microbes themselves (134), the still unfolding story of antibiotic impacts on health and environment should underscore the importance of foresight and humility regarding the risks and limits of current technology to intervene in systems that have evolved over millions of years.

\section{Conclusion}

Since the time of Forbes' observations about basic ecology (1), and the discovery of pathogens, we have made significant but still limited advances in understanding our microbial world in general, and in how the gut microbiota relates to health. At the immediate level, we understand the human microbiome to be dynamic and multiply determined through processes that are not fully known. Presently, this complexity is most accessible to the extent that we define, measure, and manipulate the gut micro environment as a relatively closed, static system within the body. Yet, emerging evidence on the interrelations of the microbiota with neural systems, physiological processes such as inflammation, stress, and broader environments suggests the need to understand microbiota-health associations by considering how immediate and proximal systems interact with more distal biological, psychological, and social systems. 
Of obvious importance is the continued advancement of our basic understanding of immediate microbiome processes, and potentially harnessing this to address dysbiosis clinically. However, the effectiveness of this approach over time without ecological consideration is unknown. The emerging consensus is that the ecologies of the microbiome interact significantly with broader ecologies. This makes a range of contextual factors important to consider for maximizing the reliability and generalizability of both clinical and basic research over time. By extension, we face the prospect that clinical efficacy in addressing dysbiosis only at the host level will be dwarfed by - or reach a point of diminishing returns against - environmental conditions that are foundational to the health of microbial systems, humans, and all life on earth. Arguably, sustainable bio-environmental systems that support microbial and general health hold the greatest value in the long term $(78,135)$.

Although many of the potential factors relating to the microbiome and brain-gut axis are currently beyond direct empirical examination, the framework proposed here can encourage progress in the difficult but necessary challenge to increase the ecological validity of microbiome research. An ecological approach also has known co-benefits for microbiome and general health (78), and the clinical and economic benefits of both prevention and environmental health in general have long been clear. The greatest dividends would therefore come from efforts aimed at micro-level advances that increasingly consider the influence of broader systems, while supporting the health and sustainability of those systems. 


\section{References}

1. Forbes SA. The Lake as a Microcosm. Champaign : Illinois Natural History Survey; 1925.

2. Engel GL. The need for a new medical model: A challenge for biomedicine. Science. 1977;196(4286):129-36.

3. Kirch DG, Mitchell K, Ast C. The new 2015 MCAT testing competencies. JAMA: Journal of the American Medical Association. 2013;310(21):2243-4.

4. Mitchell K, Lewis RS, Satterfield J, Hong BA. The new Medical College Admission Test: Implications for teaching psychology. American Psychologist. 2016;71(2):125-35.

5. Turnbaugh PJ, Ley RE, Hamady M, Fraser-Liggett C, Knight R, Gordon JI. The human microbiome project: exploring the microbial part of ourselves in a changing world. Nature. 2007;449(7164):804-10.

6. Blaser MJ. The microbiome revolution. The Journal of Clinical Investigation. 2014;124(10):4162-5.

7. Burokas A, Moloney RD, Dinan TG, Cryan JF. Chapter One - Microbiota Regulation of the Mammalian Gut-Brain Axis. In: Sima S, Geoffrey Michael G, eds. Advances in Applied Microbiology: Academic Press; 2015:1-62.

8. Clemente Jose C, Ursell Luke K, Parfrey Laura W, Knight R. The Impact of the Gut Microbiota on Human Health: An Integrative View. Cell. 2012;148(6):1258-70.

9. Costello EK, Stagaman K, Dethlefsen L, Bohannan BJM, Relman DA. The application of ecological theory towards an understanding of the human microbiome. Science (New York, N.Y.). 2012;336(6086):1255-62. 
10. Trosvik P, de Muinck EJ. Ecology of bacteria in the human gastrointestinal tractidentification of keystone and foundation taxa. Microbiome. 2015;3:44.

11. Sharpton TJ, Gaulke CA. Modeling the Context-Dependent Associations between the Gut Microbiome, Its Environment, and Host Health. MBio. 2015;6(5):01367-15.

12. Rynkiewicz EC, Pedersen AB, Fenton A. An ecosystem approach to understanding and managing within-host parasite community dynamics. Trends in parasitology. 2015;31(5):212-21.

13. Liddicoat C, Waycott M, Weinstein P. Environmental Change and Human Health: Can Environmental Proxies Inform the Biodiversity Hypothesis for Protective MicrobialHuman Contact? BioScience. 2016;66(12):1023-34.

14. Ley RE, Knight R, Gordon JI. The human microbiome: eliminating the biomedical/environmental dichotomy in microbial ecology. Environmental Microbiology. 2007;9(1):3-4.

15. Aroniadis OC, Drossman DA, Simren M. A Perspective on Brain-Gut Communication: The American Gastroenterology Association and American Psychosomatic Society Joint Symposium on Brain-gut Interactions and the Intestinal Microenvironment. Psychosom Med. doi: 10.1097/PSY.0000000000000431.

16. Levin SA. Self-organization and the Emergence of Complexity in Ecological Systems. BioScience. 2005;55(12):1075-9.

17. Levin SA. Ecosystems and the Biosphere as Complex Adaptive Systems. Ecosystems. $1998 ; 1(5): 431-6$.

18. Gilbert JA, Henry C. Predicting ecosystem emergent properties at multiple scales. Environmental Microbiology Reports. 2015;7(1):20-2. 
19. Ponge J-F. Emergent properties from organisms to ecosystems: towards a realistic approach. Biological Reviews of the Cambridge Philosophical Society. 2005;80(3):40311.

20. Hallam SJ, McCutcheon JP. Microbes don't play solitaire: how cooperation trumps isolation in the microbial world. Environmental Microbiology Reports. 2015;7(1):26-8.

21. Biteen JS, Blainey PC, Cardon ZG, Chun MY, Church GM, Dorrestein PC, Fraser SE, Gilbert JA, Jansson JK, Knight R, Miller JF, Ozcan A, Prather KA, Quake SR, Ruby EG, Silver PA, Taha S, van den Engh G, Weiss PS, Wong GCL, Wright AT, Young TD. Tools for the Microbiome: Nano and Beyond. Acs Nano. 2016;10(1):6-37.

22. Faust K, Lahti L, Gonze D, de Vos WM, Raes J. Metagenomics meets time series analysis: unraveling microbial community dynamics. Current Opinion in Microbiology. 2015;25:56-66.

23. Sung J, Hale V, Merkel AC, Kim PJ, Chia N. Metabolic modeling with Big Data and the gut microbiome. Applied and Translational Genomics. 2016;10:10-5.

24. Sallis JF, Owen N. Ecological models of health behavior. In: Glanz K, Rimer BK, Viswanath KV, eds. Health behavior: Theory, research, and practice (5th ed.). San Francisco, CA, US: Jossey-Bass; 2015:43-64.

25. Stokols D. Establishing and maintaining healthy environments: Toward a social ecology of health promotion. American Psychologist. 1992;47(1):6-22.

26. Schneider M, Stokols D. Multilevel theories of behavior change: A social ecological framework. In: Shumaker SA, Ockene JK, Riekert KA, eds. The handbook of health behavior change (3rd ed.). New York, NY, US: Springer Publishing Co; 2009:85-105. 
27. Dworkin SF, von Korff MR, LeResche L. Epidemiologic studies of chronic pain: A dynamic-ecologic perspective. Annals of Behavioral Medicine. 1992;14(1):3-11.

28. Bronfenbrenner U, Morris PA. The Bioecological Model of Human Development. Handbook of Child Psychology: John Wiley \& Sons, Inc.; 2007.

29. Wilcox BA, Aguirre AA, Daszak P, Horwitz P, Martens P, Parkes M, Patz JA, WaltnerToews D. EcoHealth: A Transdisciplinary Imperative for a Sustainable Future. EcoHealth. 2004;1(1):3-5.

30. Riegelman RK, Kirkwood B. One Health : from AIDS to Zika; 2018.

31. Qin J, Li R, Raes J, Arumugam M, Burgdorf KS, Manichanh C, Nielsen T, Pons N, Levenez F, Yamada T, Mende DR, Li J, Xu J, Li S, Li D, Cao J, Wang B, Liang H, Zheng H, Xie Y, Tap J, Lepage P, Bertalan M, Batto J-M, Hansen T, Le Paslier D, Linneberg A, Nielsen HB, Pelletier E, Renault P, Sicheritz-Ponten T, Turner K, Zhu H, Yu C, Li S, Jian M, Zhou Y, Li Y, Zhang X, Li S, Qin N, Yang H, Wang J, Brunak S, Doré J, Guarner F, Kristiansen K, Pedersen O, Parkhill J, Weissenbach J, Meta HITC, Bork P, Ehrlich SD, Wang J. A human gut microbial gene catalog established by metagenomic sequencing. Nature. 2010;464(7285):59-65.

32. Hoarau G, Mukherjee PK, Gower-Rousseau C, Hager C, Chandra J, Retuerto MA, Neut C, Vermeire S, Clemente J, Colombel JF, Fujioka H, Poulain D, Sendid B, Ghannoum MA. Bacteriome and Mycobiome Interactions Underscore Microbial Dysbiosis in Familial Crohn's Disease. MBio. 2016;7(5).

33. Goodrich JK, Davenport ER, Waters JL, Clark AG, Ley RE. Cross-species comparisons of host genetic associations with the microbiome. Science. 2016;352(6285):532-5. 
34. Goodrich Julia K, Waters Jillian L, Poole Angela C, Sutter Jessica L, Koren O, Blekhman R, Beaumont M, Van Treuren W, Knight R, Bell Jordana T, Spector Timothy D, Clark Andrew G, Ley Ruth E. Human Genetics Shape the Gut Microbiome. Cell. 2014;159(4):789-99.

35. Stilling RM, Dinan TG, Cryan JF. Microbial genes, brain \& behaviour-epigenetic regulation of the gut-brain axis. Genes, Brain and Behavior. 2014;13(1):69-86.

36. McNally L, Brown SP. Building the microbiome in health and disease: niche construction and social conflict in bacteria. Philosophical Transactions of the Royal Society B: Biological Sciences. 2015;370(1675).

37. Britton RA, Young VB. Interaction between the intestinal microbiota and host in Clostridium difficile colonization resistance. Trends in microbiology. 2012;20(7):313-9.

38. O'Hara AM, Shanahan F. The gut flora as a forgotten organ. EMBO reports. 2006;7(7):688-93.

39. Rook GAW. Regulation of the immune system by biodiversity from the natural environment: An ecosystem service essential to health. Proceedings of the National Academy of Sciences. 2013;110(46):18360-7.

40. Gibbons SM, Gilbert JA. Microbial diversity - exploration of natural ecosystems and microbiomes. Current Opinion in Genetics \& Development. 2015;35:66-72.

41. Dinan TG, Stilling RM, Stanton C, Cryan JF. Collective unconscious: How gut microbes shape human behavior. Journal of Psychiatric Research. 2015;63:1-9.

42. Mayer EA. Gut feelings: the emerging biology of gut-brain communication. Nat Rev Neurosci. 2011;12(8):453-66. 
43. Cryan JF, Dinan TG. Gut microbiota: Microbiota and neuroimmune signallingMetchnikoff to microglia. Nat Rev Gastroenterol Hepatol. 2015;12(9):494-6.

44. de Clercq N, Frissen MN, Groen AK, Nieuwdorp M. Gut microbiota and the gut-brain axis: New insights in the pathophysiology of metabolic syndrome. Psychosom Med. 2017. doi: 10.1097/PSY.0000000000000495

45. Le Chatelier E, Nielsen T, Qin J, Prifti E, Hildebrand F, Falony G, Almeida M, Arumugam M, Batto J-M, Kennedy S, Leonard P, Li J, Burgdorf K, Grarup N, Jorgensen T, Brandslund I, Nielsen HB, Juncker AS, Bertalan M, Levenez F, Pons N, Rasmussen S, Sunagawa S, Tap J, Tims S, Zoetendal EG, Brunak S, Clement K, Dore J, Kleerebezem M, Kristiansen K, Renault P, Sicheritz-Ponten T, de Vos WM, Zucker J-D, Raes J, Hansen T, Meta HITc, Bork P, Wang J, Ehrlich SD, Pedersen O. Richness of human gut microbiome correlates with metabolic markers. Nature. 2013;500(7464):541-6.

46. Cox LM, Yamanishi S, Sohn J, Alekseyenko AV, Leung JM, Cho I, Kim S, Li H, Gao Z, Mahana D, Rodriguez JGZ, Rogers AB, Robine N, Loke Pn, Blaser MJ. Altering the intestinal microbiota during a critical developmental window has lasting metabolic consequences. Cell. 2014;158(4):705-21.

47. Sanmiguel CP, Jacobs J, Gupta A, Ju T, Stains J, Coveleskie K, Lagishetty V, Balioukova A, Chen Y, Dutson E, Mayer E, Labus JS. Surgically induced changes in gut microbiome and hedonic eating as related to weight loss: Preliminary findings in obese women undergoing bariatric surgery. Psychosom Med. 2017. Doi: 10.1097/PSY.0000000000000494 
48. Lyte M, Fodor AA, Chapman CD, Martin GG, Perez-Chanona E, Jobin C, Dess NK. Gut Microbiota and a Selectively Bred Taste Phenotype: A Novel Model of MicrobiomeBehavior Relationships. Psychosom Med. 2016;78(5):610-9.

49. Bhargava P, Mowry EM. Gut Microbiome and Multiple Sclerosis. Current Neurology and Neuroscience Reports. 2014;14(10):1-8.

50. Gur TL, Bailey MT. Effects of Stress on Commensal Microbes and Immune System Activity. Advances in Experimental Medicine and Biology. 2016;874:289-300.

51. Tulic MK, Piche T, Verhasselt V. Lung-gut cross-talk: evidence, mechanisms and implications for the mucosal inflammatory diseases. Clinical \& Experimental Allergy. 2016;46(4):519-28.

52. Möller CM, Olsa EJA, Ginty AT, Rapelje AL, Tindall CL, Holesh LA, Petersen KL, Conklin SM. Influence of acute multi-species and multi-strain probiotic supplementation on cardiovascular function and reactivity to psychological stress in young adults: a double-blind, randomized, placebo-controlled trial. Psychosom Med. 2017. doi: 10.1097/PSY.0000000000000489.

53. Dinan TG, Cryan JF. Regulation of the stress response by the gut microbiota: Implications for psychoneuroendocrinology. Psychoneuroendocrinology. 2012;37(9):1369-78.

54. Moloney RD, Johnson AC, O'Mahony SM, Dinan TG, Greenwood-Van Meerveld B, Cryan JF. Stress and the microbiota-gut-brain axis in visceral pain: Relevance to irritable bowel syndrome. CNS Neuroscience \& Therapeutics. 2016;22(2):102-17.

55. Gur TL, Worly BL, Bailey MT. Stress and the Commensal Microbiota: Importance in Parturition and Infant Neurodevelopment. Frontiers in Psychiatry. 2015;6:5. 
56. Mayer EA, Knight R, Mazmanian SK, Cryan JF, Tillisch K. Gut Microbes and the Brain: Paradigm Shift in Neuroscience. The Journal of Neuroscience. 2014;34(46):15490-6.

57. Dinan TG, Stanton C, Cryan JF. Psychobiotics: A Novel Class of Psychotropic. Biological Psychiatry. 2013;74(10):720-6.

58. Tillisch K, Mayer E, Gupta A, Gill Z, Brazeilles R, Le Nevé B, van Hylckama Vlieg J, Guyonnet D, Derrien M, Labus J. Brain structure and response to emotional stimuli as related to gut microbial profiles in healthy women. Psychosom Med. 2017. Doi: 10.1097/PSY.0000000000000493.

59. Kim H, Park Y-J. The Association Between Temperament and Microbiota in Healthy Individuals: A Pilot Study. Psychosomatic Medicine. 9000;Publish Ahead of Print.

60. Dinan T, Cryan J. Brain-gut-microbiota axis in psychiatry: novel paradigm or false dawn? Psychosomatic Medicine. 2017.

61. Fouhy F, Ross RP, Fitzgerald GF, Stanton C, Cotter PD. Composition of the early intestinal microbiota. Gut Microbes. 2012;3(3):203-20.

62. Browne HP, Forster SC, Anonye BO, Kumar N, Neville BA, Stares MD, Goulding D, Lawley TD. Culturing of 'unculturable' human microbiota reveals novel taxa and extensive sporulation. Nature. 2016;533(7604):543-6.

63. Amaral WZ, Lubach GR, Proctor A, Lyte M, Phillips GJ, Coe CL. Social influences on prevotella and the gut microbiome of young monkeys. Psychosom Med. doi: 10.1097/PSY.0000000000000454.

64. Montiel-Castro A, González-Cervantes R, Bravo-Ruiseco G, Pacheco-Lopez G. The microbiota-gut-brain axis: neurobehavioral correlates, health and sociality. Frontiers in Integrative Neuroscience. 2013;7(70). 
65. Bailey MT. The contributing role of the intestinal microbiota in stressor-induced increases in susceptibility to enteric infection and systemic immunomodulation. Hormones and Behavior. 2012;62(3):286-94.

66. Hsiao Elaine Y, McBride Sara W, Hsien S, Sharon G, Hyde Embriette R, McCue T, Codelli Julian A, Chow J, Reisman Sarah E, Petrosino Joseph F, Patterson Paul H, Mazmanian Sarkis K. Microbiota Modulate Behavioral and Physiological Abnormalities Associated with Neurodevelopmental Disorders. Cell. 2013;155(7):1451-63.

67. Yatsunenko T, Rey FE, Manary MJ, Trehan I, Dominguez-Bello MG, Contreras M, Magris M, Hidalgo G, Baldassano RN, Anokhin AP, Heath AC, Warner B, Reeder J, Kuczynski J, Caporaso JG, Lozupone CA, Lauber C, Clemente JC, Knights D, Knight R, Gordon JI. Human gut microbiome viewed across age and geography. Nature. 2012;486(7402):222-7.

68. Gillings MR. Lateral gene transfer, bacterial genome evolution, and the Anthropocene. Annals of The New York Academy of Sciences. 2017;1389(1):20-36.

69. Smillie CS, Smith MB, Friedman J, Cordero OX, David LA, Alm EJ. Ecology drives a global network of gene exchange connecting the human microbiome. Nature. 2011;480(7376):241-4.

70. Hehemann JH, Kelly AG, Pudlo NA, Martens EC, Boraston AB. Bacteria of the human gut microbiome catabolize red seaweed glycans with carbohydrate-active enzyme updates from extrinsic microbes. Proceedings of the National Academy of Sciences of the United States of America. 2012;109(48):19786-91.

71. Xu Z, Knight R. Dietary effects on human gut microbiome diversity. The British Journal of Nutrition. 2015;113(Suppl 0):S1-S5. 
72. Miller GE, Engen PA, Gillevet PM, Shaikh M, Sikaroodi M, Forsyth CB, Mutlu E, Keshavarzian A. Lower Neighborhood Socioeconomic Status Associated with Reduced Diversity of the Colonic Microbiota in Healthy Adults. PLoS ONE. 2016;11(2):e0148952.

73. Oriach CS, Robertson RC, Stanton C, Cryan JF, Dinan TG. Food for thought: The role of nutrition in the microbiota-gut-brain axis. Clinical Nutrition Experimental. 2016;6:25-38.

74. Clarke SF, Murphy EF, O'Sullivan O, Lucey AJ, Humphreys M, Hogan A, Hayes P, O'Reilly M, Jeffery IB, Wood-Martin R, Kerins DM, Quigley E, Ross RP, O'Toole PW, Molloy MG, Falvey E, Shanahan F, Cotter PD. Exercise and associated dietary extremes impact on gut microbial diversity. Gut. 2014.

75. Cook MD, Allen JM, Pence BD, Wallig MA, Gaskins HR, White BA, Woods JA. Exercise and gut immune function: evidence of alterations in colon immune cell homeostasis and microbiome characteristics with exercise training. Immunology and Cell Biology. 2016;94(2):158-63.

76. Chioro A, Coll-Seck AM, Høie B, Moeloek N, Motsoaledi A, Rajatanavin R, Touraine M. Antimicrobial resistance: a priority for global health action. World Health Organization; 2015.

77. Blaser MJ. Missing microbes : how the overuse of antibiotics is fueling our modern plagues. New York: Picador; 2015.

78. World Health Organization and Secretariat of the Convention on Biological Diversity. World Health Organization and Secretariat of the Convention on Biological Diversity, Connecting Global Priorities: Biodiversity and Human Health, a State of Knowledge Review. Geneva: World Health Organization; 2015. 
79. Van Boeckel TP, Gandra S, Ashok A, Caudron Q, Grenfell BT, Levin SA, Laxminarayan R. Global antibiotic consumption 2000 to 2010: an analysis of national pharmaceutical sales data. The Lancet Infectious Diseases. 2014;14(8):742-50.

80. Van Boeckel TP, Brower C, Gilbert M, Grenfell BT, Levin SA, Robinson TP, Teillant A, Laxminarayan R. Global trends in antimicrobial use in food animals. Proceedings of the National Academy of Sciences. 2015;112(18):5649-54.

81. Spellberg B, Bartlett JG, Gilbert DN. The Future of Antibiotics and Resistance. New England Journal of Medicine. 2013;368(4):299-302.

82. Neu J, Rushing J. Cesarean versus Vaginal Delivery: Long term infant outcomes and the Hygiene Hypothesis. Clinics in perinatology. 2011;38(2):321-31.

83. Dominguez-Bello MG, De Jesus-Laboy KM, Shen N, Cox LM, Amir A, Gonzalez A, Bokulich NA, Song SJ, Hoashi M, Rivera-Vinas JI, Mendez K, Knight R, Clemente JC. Partial restoration of the microbiota of cesarean-born infants via vaginal microbial transfer. Nat Med. 2016;22(3):250-3.

84. Nayfach S, Rodriguez-Mueller B, Garud N, Pollard KS. An integrated metagenomics pipeline for strain profiling reveals novel patterns of bacterial transmission and biogeography. Genome Research. 2016;26(11):1612-25.

85. Rook GAW, Knight R. Environmental microbial diversity and noncommunicable diseases. World Health Organization and Secretariat of the Convention on Biological Diversity, Connecting Global Priorities: Biodiversity and Human Health, a State of Knowledge Review. Geneva: World Health Organization; 2015:150-63.

86. Rook GAW, Raison CL, Lowry CA. Microbial 'old friends', immunoregulation and socioeconomic status. Clinical and Experimental Immunology. 2014;177(1):1-12. 
87. Martin LJ, Adams RI, Bateman A, Bik HM, Hawks J, Hird SM, Hughes D, Kembel SW, Kinney K, Kolokotronis S-O, Levy G, McClain C, Meadow JF, Medina RF, Mhuireach G, Moreau CS, Munshi-South J, Nichols LM, Palmer C, Popova L, Schal C, Täubel M, Trautwein M, Ugalde JA, Dunn RR. Evolution of the indoor biome. Trends in Ecology \& Evolution. 2015;30(4):223-32.

88. Chase J, Fouquier J, Zare M, Sonderegger DL, Knight R, Kelley ST, Siegel J, Caporaso JG. Geography and Location are the Primary Drivers of Office Microbiome Composition. mSystems. 2016;1(2).

89. Leung MHY, Lee PKH. The roles of the outdoors and occupants in contributing to a potential pan-microbiome of the built environment: a review. Microbiome. 2016;4.

90. Gilbert JA, Jansson JK, Knight R. The Earth Microbiome project: successes and aspirations. BMC Biology. 2014;12(1):1-4.

91. Cardinale BJ, Duffy JE, Gonzalez A, Hooper DU, Perrings C, Venail P, Narwani A, Mace GM, Tilman D, Wardle DA, Kinzig AP, Daily GC, Loreau M, Grace JB, Larigauderie A, Srivastava DS, Naeem S. Biodiversity loss and its impact on humanity. Nature. 2012;486(7401):59-67.

92. Young OR, Berkhout F, Gallopin GC, Janssen MA, Ostrom E, van der Leeuw S. The globalization of socio-ecological systems: An agenda for scientific research. Global Environmental Change. 2006;16(3):304-16.

93. Scheffers BR, De Meester L, Bridge TCL, Hoffmann AA, Pandolfi JM, Corlett RT, Butchart SHM, Pearce-Kelly P, Kovacs KM, Dudgeon D, Pacifici M, Rondinini C, Foden WB, Martin TG, Mora C, Bickford D, Watson JEM. The broad footprint of climate change from genes to biomes to people. Science. 2016;354(6313). 
94. Corlett RT. The Anthropocene concept in ecology and conservation. Trends in Ecology \& Evolution. 2015;30(1).

95. Jones BA, Grace D, Kock R, Alonso S, Rushton J, Said MY, McKeever D, Mutua F, Young J, McDermott J, Pfeiffer DU. Zoonosis emergence linked to agricultural intensification and environmental change. Proceedings of the National Academy of Sciences. 2013;110(21):8399-404.

96. Hunter D, Burlingame B, Remans R. Biodiversity and nutrition in World Health Organization and Secretariat of the Convention on Biological Diversity, Connecting Global Priorities: Biodiversity and Human Health, a State of Knowledge Review. Geneva: World Health Organization; 2015:97-129.

97. Tilman D, Clark M. Global diets link environmental sustainability and human health. Nature. 2014;515(7528):518-22.

98. Suez J, Korem T, Zeevi D, Zilberman-Schapira G, Thaiss CA, Maza O, Israeli D, Zmora N, Gilad S, Weinberger A, Kuperman Y, Harmelin A, Kolodkin-Gal I, Shapiro H, Halpern Z, Segal E, Elinav E. Artificial sweeteners induce glucose intolerance by altering the gut microbiota. Nature. 2014;514(7521):181-6.

99. World Health Organization. Global Action Plan on Antimicrobial Resistance. Geneva: World Health Organization; 2015.

100. Czaplewski L, Bax R, Clokie M, Dawson M, Fairhead H, Fischetti VA, Foster S, Gilmore BF, Hancock REW, Harper D, Henderson IR, Hilpert K, Jones BV, Kadioglu A, Knowles D, Ólafsdóttir S, Payne D, Projan S, Shaunak S, Silverman J, Thomas CM, Trust TJ, Warn P, Rex JH. Alternatives to antibiotics-a pipeline portfolio review. The Lancet Infectious Diseases. 2016;16(2):239-51. 
101. So AD, Shah TA, Roach S, Ling Chee Y, Nachman KE. An Integrated Systems Approach is Needed to Ensure the Sustainability of Antibiotic Effectiveness for Both Humans and Animals. The Journal of Law, Medicine \& Ethics. 2015;43(S3):38-45.

102. Baum A, Garofalo JP, Yali AM. Socioeconomic status and chronic stress. Does stress account for SES effects on health? Annals of The New York Academy of Sciences. 1999;896:131-44.

103. Seeman T, Epel E, Gruenewald T, Karlamangla A, McEwen BS. Socio-economic differentials in peripheral biology: cumulative allostatic load. Annals of The New York Academy of Sciences. 2010;1186:223-39.

104. Upchurch DM, Stein J, Greendale GA, Chyu L, Tseng C-H, Huang M-H, Lewis TT, Kravitz HM, Seeman T. A longitudinal investigation of race, socioeconomic status, and psychosocial mediators of allostatic load in midlife women: Findings from the Study of Women's Health Across the Nation. Psychosom Med. 2015;77(4):402-12.

105. Chiang JJ, Bower JE, Almeida DM, Irwin MR, Seeman TE, Fuligni AJ. Socioeconomic status, daily affective and social experiences, and inflammation during adolescence. Psychosom Med. 2015;77(3):256-66.

106. Chen E, Miller GE, Lachman ME, Gruenewald TL, Seeman TE. Protective factors for adults from low-childhood socioeconomic circumstances: The benefits of shift-andpersist for allostatic load. Psychosom Med. 2012;74(2):178-86.

107. Chen E, Strunk RC, Trethewey A, Schreier HMC, Maharaj N, Miller GE. Resilience in Low Socioeconomic Status Children with Asthma: Adaptations to Stress. The Journal of allergy and clinical immunology. 2011;128(5):970-6. 
108. Sturgeon JA, Arewasikporn A, Okun MA, Davis MC, Ong AD, Zautra AJ. The Psychosocial Context of Financial Stress: Implications for Inflammation and Psychological Health. Psychosom Med. 2016;78(2):134-43.

109. Kershaw KN, Lewis TT, Roux AVD, Jenny NS, Liu K, Penedo FJ, Carnethon MR. Selfreported experiences of discrimination and inflammation among men and women: The multi-ethnic study of atherosclerosis. Health Psychology. 2016;35(4):343-50.

110. Matthews KA, Chang Y, Bromberger JT, Karvonen-Gutierrez CA, Kravitz HM, Thurston RC, Montez JK. Childhood Socioeconomic Circumstances, Inflammation, and Hemostasis Among Midlife Women: Study of Women's Health Across the Nation. Psychosom Med. 2016;78(3):311-8.

111. Freeman JA, Bauldry S, Volpe VV, Shanahan MJ, Shanahan L. Sex Differences in Associations Between Subjective Social Status and C-Reactive Protein in Young Adults. Psychosom Med. 2016;78(5):542-51.

112. World Health Organization. Antimicrobial resistance: global report on surveillance. World Health Organization; 2014.

113. Yang Z, Guo Z, Qiu C, Li Y, Feng X, Liu Y, Zhang Y, Pang P, Wang P, Zhou Q, Han L, Dai W. Preliminary analysis showed country-specific gut resistome based on 1267 feces samples. Gene. 2016;581(2):178-82.

114. Wang FH, Qiao M, Su JQ, Chen Z, Zhou X, Zhu YG. High Throughput Profiling of Antibiotic Resistance Genes in Urban Park Soils with Reclaimed Water Irrigation. Environmental Science \& Technology. 2014;48(16):9079-85. 
115. Boxall ABA, Kretsch CE. Biodiversity, health care \& pharmaceuticals. World Health Organization and Secretariat of the Convention on Biological Diversity, Connecting Global Priorities: Biodiversity and Human Health, a State of Knowledge Review. Geneva: World Health Organization; 2015:170-9.

116. Beketov MA, Kefford BJ, Schäfer RB, Liess M. Pesticides reduce regional biodiversity of stream invertebrates. Proceedings of the National Academy of Sciences. 2013;110(27):11039-43.

117. Pedersen AB, Fenton A. Emphasizing the ecology in parasite community ecology. Trends in Ecology \& Evolution. 2007;22(3):133-9.

118. Romanelli C, Capon A, Maiero M, Campbell-Lendrum D. Climate change, biodiversity and human health. World Health Organization and Secretariat of the Convention on Biological Diversity, Connecting Global Priorities: Biodiversity and Human Health, a State of Knowledge Review. Geneva: World Health Organization; 2015:222-37.

119. Lagier JC, Khelaifia S, Alou MT, Ndongo S, Dione N, Hugon P, Caputo A, Cadoret F, Traore SI, Seck EH, Dubourg G, Durand G, Mourembou G, Guilhot E, Togo A, Bellali S, Bachar D, Cassir N, Bittar F, Delerce J, Mailhe M, Ricaboni D, Bilen M, Nieko N, Badiane NMD, Valles C, Mouelhi D, Diop K, Million M, Musso D, Abrahao J, Azhar EI, Bibi F, Yasir M, Diallo A, Sokhna C, Djossou F, Vitton V, Robert C, Rolain JM, La Scola B, Fournier PE, Levasseur A, Raoult D. Culture of previously uncultured members of the human gut microbiota by culturomics. Nature Microbiology. 2016;1(12).

120. McGill BJ, Dornelas M, Gotelli NJ, Magurran AE. Fifteen forms of biodiversity trend in the Anthropocene. Trends in Ecology \& Evolution. 2015;30(2):104-13. 
121. Mai V, Prosperi M, Yaghjyan L. Moving microbiota research toward establishing causal associations that represent viable targets for effective public health interventions. Annals of Epidemiology. 2016;26(5):306-10.

122. Curtis T. Theory and the microbial world. Environmental Microbiology. 2007;9(1):1-.

123. Motesharrei S, Rivas J, Kalnay E, Asrar GR, Busalacchi AJ, Cahalan RF, Cane MA, Colwell RR, Feng K, Franklin RS, Hubacek K, Miralles-Wilhelm F, Miyoshi T, Ruth M, Sagdeev R, Shirmohammadi A, Shukla J, Srebric J, Yakovenko VM, Zeng N. Modeling sustainability: population, inequality, consumption, and bidirectional coupling of the Earth and Human Systems. National Science Review. 2016;3(4):470-94.

124. Relman DA. The human microbiome: ecosystem resilience and health. Nutrition reviews. 2012;70(Suppl 1):S2-S9.

125. Ramos T, Stephens B. Tools to improve built environment data collection for indoor microbial ecology investigations. Building and Environment. 2014;81:243-57.

126. Goodrich Julia K, Di Rienzi Sara C, Poole Angela C, Koren O, Walters William A, Caporaso JG, Knight R, Ley Ruth E. Conducting a Microbiome Study. Cell. 2014;158(2):250-62.

127. Blanco-Míguez A, Gutiérrez-Jácome A, Fdez-Riverola F, Lourenço A, Sánchez B. MAHMI database: a comprehensive MetaHit-based resource for the study of the mechanism of action of the human microbiota. Database: The Journal of Biological Databases and Curation. 2017;2017:baw157.

128. Hanson BM, Weinstock GM. The importance of the microbiome in epidemiologic research. Annals of Epidemiology. 2016;26(5):301-5. 
129. Kyrpides NC, Eloe-Fadrosh EA, Ivanova NN. Microbiome Data Science: Understanding Our Microbial Planet. Trends in microbiology. 2016;24(6):425-7.

130. The Human Microbiome Project Consortium. Structure, Function and Diversity of the Healthy Human Microbiome. Nature. 2012;486(7402):207-14.

131. Brüssow H. Biome engineering-2020. Microbial Biotechnology. 2016;9(5):553-63.

132. Brandt L. Fecal microbiota therapy with a focus on C. difficile infection. Psychosom Medicine. 2017. DOI: 10.1097/PSY.0000000000000511.

133. Sundin J, Öhman L, Simren M. Understanding the Gut Microbiota in Inflammatory and Functional Gastrointestinal Diseases. Psychosom Med. doi: 10.1097/PSY.0000000000000470.

134. Blaser MJ, Cardon ZG, Cho MK, Dangl JL, Donohue TJ, Green JL, Knight R, Maxon ME, Northen TR, Pollard KS, Brodie EL. Toward a Predictive Understanding of Earth's Microbiomes to Address 21st Century Challenges. MBio. 2016;7(3).

135. Whitmee S, Haines A, Beyrer C, Boltz F, Capon AG, de Souza Dias BF, Ezeh A, Frumkin H, Gong P, Head P, Horton R, Mace GM, Marten R, Myers SS, Nishtar S, Osofsky SA, Pattanayak SK, Pongsiri MJ, Romanelli C, Soucat A, Vega J, Yach D. Safeguarding human health in the Anthropocene epoch: report of The Rockefeller Foundation-Lancet Commission on planetary health. The Lancet;386(10007):1973-2028. 


\section{FIGURE CAPTION}

Figure 1. Biopsychosocial Ecology of the Human Microbiome and health. The biopsychosocial (BPS) ecological framework illustrated here extends Engel's general BPS model (1977) by explicitly considering the dynamic relations across the BPS domains and their various levels, characterizing environmental and human factors as dynamic interactive processes that comprise a global ecological system over time. As an ecological system, the biological, psychological, and social factors are mutually determined and fluid between these domains and across levels (immediate, proximal, intermediate, and distal) within each. Health of the microbiome and neural systems may thus be influenced by health of the microbial ecologies of humans and their physical environments as well as broader-level environmental and social factors in which these myriad microbial ecologies and humans participate. Concept and copyright by Karl J. Maier, $\mathrm{PhD}$ (first author). Illustrated by Design Dedeaux. 
Figure 1

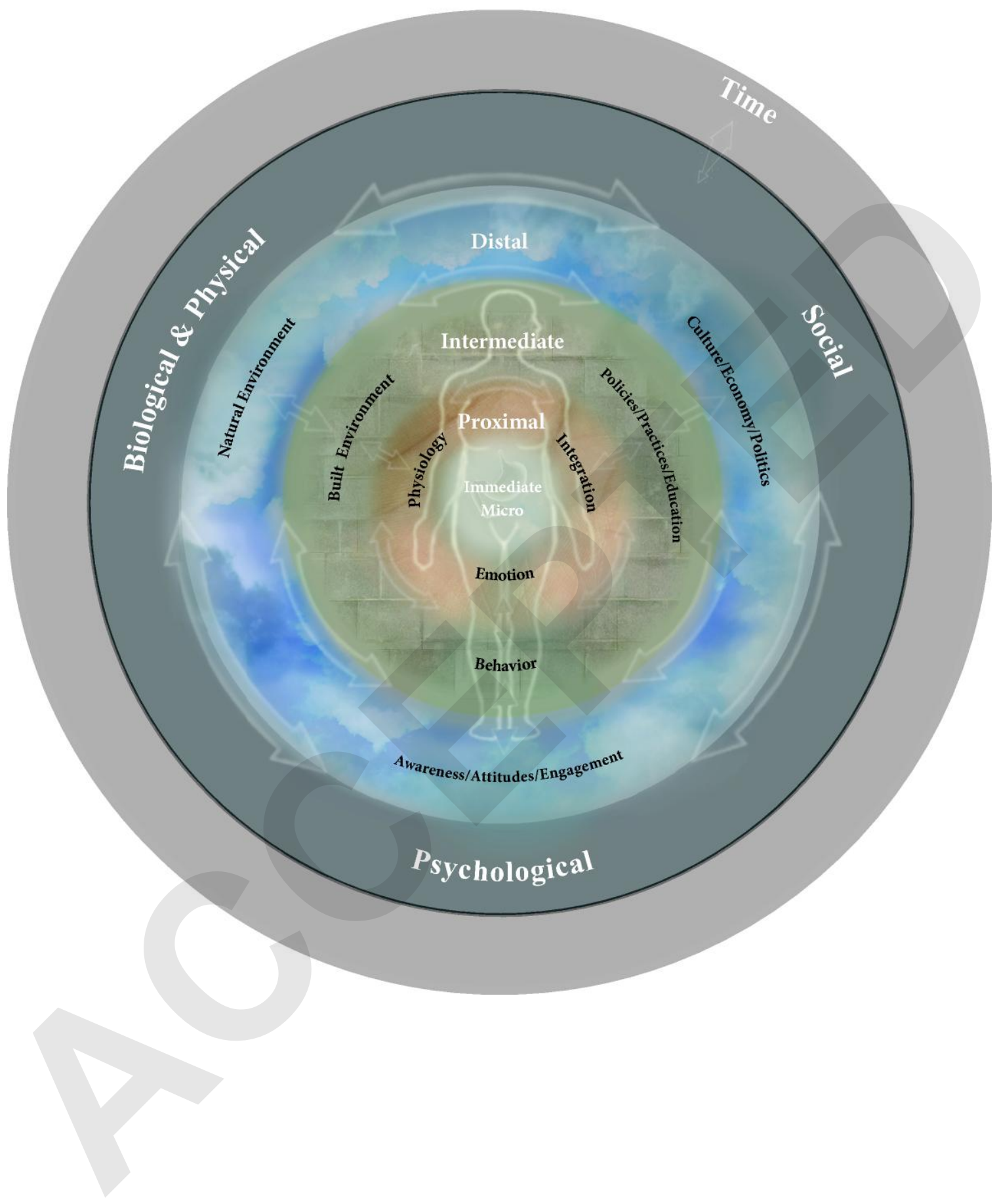

